\title{
Glycosylation of proteins of human skin fibroblasts is changed by rosmarinic acid
}

\author{
Radziejewska Iwona $^{1}$ (D) Supruniuk Katarzyna ${ }^{1}$
}

Received: 20 May 2019 / Accepted: 10 September 2019 /Published online: 25 October 2019

(C) The Author(s) 2019

\begin{abstract}
Glycosylation is a common post-translational process of protein modification. Glycans participate in many crucial biological functions like cell differentiation, cell adhesion, cell-cell interactions, and regulation of signaling pathways. Rosmarinic acid (RA) is a natural flavonoid with many pharmacological activities including anti-inflammatory, anti-oxidative, anti-bacterial, or anti-fibrotic. In this study, we aimed to determine the effect of 25,50 , and $100 \mu \mathrm{M}$ rosmarinic acid on specific carbohydrate antigens in human skin fibroblasts. ELISA-liked test with biotinylated lectins was used to assess the level of sugar structures in cell lysates and culture supernatant. RT-PCR was applied to determine mRNA of selected glycosyltransferases responsible for formation of sugar antigens. Rosmarinic acid inhibited the expression of Tn, $\mathrm{T}$ antigens and their sialylated forms, fucosylated antigens, di NAclactosamine, and mannose antigens. All used doses of RA significantly decreased core $1 \beta 1$ 3galactosyltransferase mRNA and 25 and $50 \mu \mathrm{M}$ acid significantly inhibited GalNAc $\alpha 2$-6-sialyltransferase mRNA. The results indicate that rosmarinic acid, due to decreasing effect on specific sugar antigens, can change some of crucial carbohydrate functions in skin fibroblasts, e.g., involved in cell adhesion and cell-cell interactions.
\end{abstract}

Keywords Glycosylation · Fibroblasts $\cdot$ Rosmarinic acid

\section{Introduction}

Rosmarinic acid ( $\alpha$-o-caffeoyl-3,4-dihydroxyphenyl lactic acid; RA) (Fig. 1) is a dietary, polyphenolic compound widely distributed, e.g., in rosemary, Perilla frutescens, oregano, and mint. Its beneficial, biological effects, including anti-inflammatory, anti-oxidative, anti-bacterial, and anti-cancer, have been reported (Oliveira et al. 2019). It is said that RA can promote several pharmacological effects due to specific interactions with different parts of organic systems (Scheckel et al. 2008; Karthik et al. 2011). An increase of interest to RA is currently observed. It is and will be widely used for improvement of human health. Exploring potential interactions of the

Electronic supplementary material The online version of this article (https://doi.org/10.1007/s00210-019-01732-0) contains supplementary material, which is available to authorized users.

Radziejewska Iwona iwona@umb.edu.pl

1 Department of Medical Chemistry, Medical University of Białystok, ul. Mickiewicza 2a, 15-230 Białystok 8, Poland acid with proteins and other components of human cells provides insights into understanding the mechanisms of its action.

Glycans are structures involved in communications between cells. Glycosylation is a common post-translational modification of proteins. Carbohydrate antigens are widely expressed on the cell surfaces and in extracellular matrix (ECM) as components of different glycoproteins. They contribute significantly to many crucial, biological functions, such as cell differentiation, cell adhesion, cell-cell interactions, and regulation of signaling pathways (Sasaki et al. 2017). Glycans of the human cells are mostly linked to serine/threonine or asparagine of polypeptide chains forming $\mathrm{O}-$ or N-glycoproteins. All these carbohydrate structures are built of a common set of monosaccharides, especially galactose (Gal), fucose (Fuc), mannose (Man), Nacetylglucosamine (GlcNAc), N-acetylgalactosamine (GalNAc), and sialic acid (SA). Glycans are constructed in an ordered sequence involving the distinct substrate specificities of glycosyltransferases responsible for synthetizing glycans chains and glycosydases hydrolyzing specific glycan linkages (Ohtsubo and Marth 2006). The type of glycosylation that is finally presented at a given glycosylation site is 


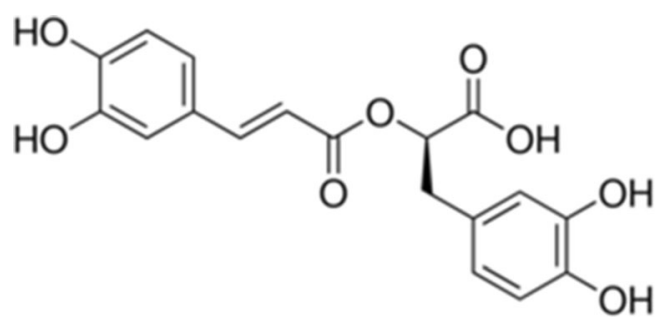

Fig. 1 The structure of rosmarinic acid (RA)

heterogeneous, giving rise in some cases to many glycoforms (Haltiwanger and Lowe 2004).

Plant lectins are powerful tools to study the structures and distribution of glycans in tissues and on cells. They are carbohydrate-binding proteins that are able to discriminate between glycans based on subtle differences in sugar structure. They can be used as research tools for detection of specific sugar structures and for localizing carbohydrates in cells and tissues in similar way that antibodies detect cell- or tissuebound protein antigens (Cui et al. 2017).

Fibroblasts are essential in maintaining skin homeostasis and participate in physiological tissue repair and skin regeneration. It has been demonstrated that cell surface glycans on fibroblasts can be affected by different external factors, e.g., during aging (Sasaki et al. 2017; Itakura et al. 2016).

In our work, we have investigated whether rosmarinic acid, common dietary compound, effects glycosylation of human fibroblasts in vitro. RA is an example of potentially non-toxic agent that by changing glycosylation pattern can effect fibroblasts function.

\section{Materials and methods}

\section{Cell culture}

The human skin fibroblasts CRL-1739 purchased from ATCC (five passage numbers were used during the study) were maintained in Dulbecco's Modified Eagle Medium (DMEM) (Gibco, USA) containing 10\% fetal bovine serum (Gibco, USA), $50 \mathrm{U} / \mathrm{ml}$ penicillin, and $50 \mu \mathrm{g} / \mathrm{ml}$ streptomycin (Sigma, USA). Cells were cultured in a humidified atmosphere of $5 \% \mathrm{CO}_{2}$ at $37{ }^{\circ} \mathrm{C}$. In the next step, the cells were seeded into 6-well plates and cultured for $24 \mathrm{~h}$ in DMEM, FBS-free medium supplemented with 25, 50, and $100 \mu \mathrm{M}$ rosmarinic acid (Roth, Germany; purity $\geq 99 \%$ ). Stock solution of RA was $2 \mathrm{mg} / 50 \mu \mathrm{L}$ DMSO (Sigma, USA) (this solution was diluted in culture medium to get proper concentrations). Then, the cells were washed with PBS and lysed with RIPA buffer (Sigma, USA) with protease inhibitors with a broad specificity for the inhibition of serine, cysteine, aspartic, and aminopeptidases: aprotinin, bestatin, E-64, leupeptin and pepstatin A (Sigma, USA), diluted 1:200 in RIPA buffer. The lysis was performed in $0.2 \mathrm{~mL}$, thin-wall plastic tubes at $4{ }^{\circ} \mathrm{C}$ for $20 \mathrm{~min}$. Then, the lysates were vortexed vigorously. The lysates and collected culture media were centrifuged at $1000 \times g$ for $5 \mathrm{~min}$ at $4{ }^{\circ} \mathrm{C}$. After that the supernatants were frozen at $-70{ }^{\circ} \mathrm{C}$ and then used for ELISA tests. For real-time PCR determinations, the monolayers were washed three times with sterile $10 \mathrm{mM}$ PBS pH 7.4, the cells were collected into sterile plastic tubes and cell membranes were disrupted using sonicator (Sonics Vibra cell) (10 W, 3 times for $15 \mathrm{~s}$ on ice). Aliquots of the homogenate were used for RNA isolation. Cells without addition of RA were treated as control.

A BCA Protein Assay Kit (Pierce, USA) was used for a protein concentration measurement.

\section{Cell viability assay}

Cell viability evaluation was carried out according to Carmichael et al. (1987), with 3-(4,5-dimethylthiazole-2-yl)2,5-diphenyltetrazolium bromide (MTT) (Sigma, USA). Confluent cells, cultured with various concentrations (10$200 \mu \mathrm{M}$ ) of RA in 6-well plates for $24 \mathrm{~h}$, were incubated in $1 \mathrm{~mL}$ of MTT solution $\left(0.5 \mathrm{mg} / \mathrm{mL}\right.$ of PBS) for $4 \mathrm{~h}$ at $37^{\circ} \mathrm{C}$ in $5 \% \mathrm{CO}_{2}$. Absorbance of converted dye in living cells was assessed at a wavelength of $570 \mathrm{~nm}$. Cell viability of fibroblasts in the presence of rosmarinic acid was calculated as percentage of control cells (without RA addition).

\section{ELISA tests}

To determine the relative level of specific sugar antigens in cell lysates and culture media, ELISA-like tests with biotinylated lectins (Vector, USA) at concentration $5 \mu \mathrm{g} / \mathrm{mL}$ were applied. The binding specificity of lectins is presented in Table 1. Aliquots of cell lysates $(50 \mu \mathrm{l} ; 100 \mu \mathrm{g}$ protein $/ \mathrm{mL})$ or media $(50 \mu \mathrm{L}$; diluted 10 times in PBS) were coated on microtiter plates and incubated at room temperature (RT) overnight. Then, there were blocking (with $100 \mu \mathrm{l}$ of $1 \%$ blocking reagent for ELISA; Roche Diagnostics, Germany) and washing steps $(100 \mu \mathrm{L}, 3$ times of washing buffer PBS, $0.05 \%$ Tween) and incubation with $100 \mu \mathrm{L}$ of proper lectins $(2 \mathrm{~h}$ at RT). Then, after incubation with $100 \mu \mathrm{L}$ of horseradish peroxidase avidin D (Vector, USA), the colored reaction was developed with $100 \mu \mathrm{L}$ of ABTS (2,2'-azinobis(3-ethylbenzthiazoline-6-sulfonic acid)-liquid substrate for horseradish peroxidase (Sigma, USA) (1 h at RT). Absorbance at $405 \mathrm{~nm}$ was read after 30-40 min. The samples were analyzed in triplicate. The wells with $1 \%$ BSA (instead of the samples) were used as negative controls.

\section{Real-time PCR}

Total RNA was isolated applying Total RNA Mini Plus Concentrator (A\&A Biotechnology, Poland), according to the manufacturer's instruction. Purity and concentration 
Table 1 Binding specificity of lectins

\begin{tabular}{ll}
\hline Origin and abbreviations of lectins & Binding preference \\
\hline Arachis hypogaea (peanut) (PNA) & Gal $\beta 1-3 \mathrm{GalNAc} \alpha 1-\mathrm{O}-\mathrm{Ser} / \mathrm{Thr}$ (T antigen) \\
Areulia auranta (AAA) & Fuc $\alpha 1-6 \mathrm{GlcNAc}$; Fuc $\alpha 1-2 \mathrm{Gal}$; Fuc $\alpha 1-3 \mathrm{GlcNAc}$ \\
Datura stramonium (DSA) & Gal $\beta 1-4 \mathrm{GlcNAc}$; GlcNAc \\
Galanthus nivalis (GNA) & Man $\alpha 1-3 \mathrm{Man}$ \\
Lotus tetragonolobus (LTA) & Fuc $\alpha 1-3 \mathrm{GlcNAc}$ \\
Maackia amurensis (MAAII) & NeuAc $\alpha 2-3 \mathrm{Gal}$ \\
Narcissus pseudonarcissus (NPA) & Man $\alpha 1-6 \mathrm{Man}$ \\
Sambucus nigra (SNA) & NeuAc $\alpha 2-6 \mathrm{Gal} / \mathrm{GalNAc}$ \\
Vicia villosa (VVA) & GalNAc $\alpha 1-\mathrm{O}-\mathrm{Ser} / \mathrm{Thr}$ (Tn antigen) \\
Ulex europaeus (UEA) & Fuc $\alpha 1-2 \mathrm{Gal}$ Fuc $\alpha 1-3 \mathrm{GlcNAc}$ \\
Wisteria floribunda (WFA) & GalNAc $\beta 1-4 \mathrm{GlcNAc}$ \\
\hline
\end{tabular}

RNA was assessed spectrophotometrically by Nanodrop 2000 (Thermo Scientific, USA). First-strand cDNA was synthesized from $1 \mu \mathrm{g}$ of total RNA by usage of Tetro cDNA Synthesis Kit (Bioline, UK). Twenty microliters of the reaction mixture containing $1 \mu$ loligo(dT) 18 primer, $1 \mu \mathrm{l}$ of dNTP mixture ( $10 \mathrm{mM}$ each), $5 \mu$ l of $5 \times$ RT Buffer, $1 \mu$ l of RiboSafe RNase Inhibitor $(10 \mathrm{u} / \mu \mathrm{l}), 1 \mu \mathrm{l}$ of Tetro Reverse Transcriptase $(200 \mathrm{u} / \mu \mathrm{l})$, and DEPC-treated water was incubated for $30 \mathrm{~min}$ (at $45^{\circ} \mathrm{C}$ ) and after that inactivated at $85^{\circ} \mathrm{C}$ for $5 \mathrm{~min}$. Realtime PCR was performed in CFX96 real-time system (BioRad, USA) using SensiFASTTM SYBR Kit (Bioline, UK). The reactions contained $2 \mu \mathrm{l}$ of twice diluted cDNA template, $0.8 \mu \mathrm{l}$ of each primer $(10 \mu \mathrm{mol} / \mathrm{L}), 10 \mu \mathrm{l} 2 \times$ SensiFAST SYBR Mix and nuclease-free water (in a final volume of $20 \mu \mathrm{l}$ ). Forward and reverse primer sequences (synthesized by Genomed, Poland) are listed in Table 2. The GAPDH (glyceraldehyde-3-phosphate dehydrogenase) was used as housekeeping gene. $95{ }^{\circ} \mathrm{C}$ for $1 \mathrm{~min}$ to activate the DNA polymerase, denaturation for $10 \mathrm{~s}$ at $95^{\circ} \mathrm{C}(40$ cycles $)$, annealing for $15 \mathrm{~s}$ at $60{ }^{\circ} \mathrm{C}$, and extension for $20 \mathrm{~s}$ at $72{ }^{\circ} \mathrm{C}$ were applied as cycling parameters. After that, the reaction was subjected to a melting protocol from 55 to $95{ }^{\circ} \mathrm{C}$ with a $0.2{ }^{\circ} \mathrm{C}$ increment and $1 \mathrm{~s}$ holding at each increment to check the specificity of the amplified products. Single product formation was verified by melting point evaluation and agarose gel electrophoresis. Water instead of mRNA samples was applied as negative control. All the samples were run in triplicate and the $\Delta \Delta \mathrm{CT}$ method was used for statistical analysis of the CT-values. The relative gene expression levels were normalized with those assessed in the untreated control.

\section{Statistical analysis}

Experimental data were displayed as mean \pm standard deviation SD from at least three independent analyses. Statistical differences were established by one-way ANOVA followed by the Duncan's multiple range post hock test; statistical significance was considered as $p<0.05$. Statistica package (StatSoft, USA) was applied to perform the calculations.

\section{Results}

\section{Assessment of cell viability}

The results of MTT test (with 10-200 $\mu \mathrm{M}$ RA) revealed that RA treatment almost had no cytotoxic effect on fibroblasts. Viability of the cells with 10-200 $\mu \mathrm{M}$ RA were as $96-100 \%$ compared with the control cells (with no RA) (Fig. 2). In all the experiments performed in the study, 25, 50, and $100 \mu \mathrm{M}$ concentration of rosmarinic acid was used. Generally, the applied doses of RA were in accordance with the amounts used by other authors (Bahri et al. 2017; Hahn et al. 2017).
Table 2 Sequences of primers used for real-time quantitative RTPCR

\begin{tabular}{lll}
\hline Gene & Forward primer $\left(5^{\prime} \rightarrow 3^{\prime}\right)$ & Reverse primer $\left(5^{\prime} \rightarrow 3^{\prime}\right)$ \\
\hline C1GalT1 & AAGCAGGGCTACATGAGTGG & GCATCTCCCCAGTGCTAAGT \\
ppGalNAcT2 & AAGAAAGACCTTCATCACAGCAATGGA & ATCAAAACCGCCCTTCAAGTCA \\
& GAA & GCA \\
ST3GalT1 & TCGGCCTGGTTCGATGA & CGCGTTCTGGGCAGTCA \\
ST6GalNAcT1 & TCTCCCTGACCCAGTCACTC & CTTCCCGAAAAGCTTCCTG \\
GAPDH & GTGACCATGAGAAGTATGACAA & CATGAGTCCTTCCACGATAC \\
\hline
\end{tabular}




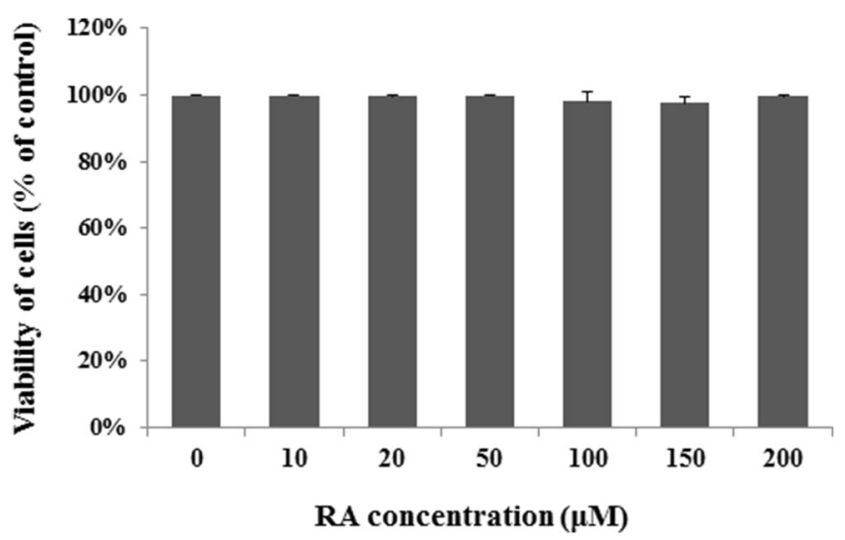

Fig. 2 Viability of human fibroblasts treated for $24 \mathrm{~h}$ with $10-200 \mu \mathrm{M}$ concentration of rosmarinic acid. Mean values \pm S.D are the mean of triplicate cultures

\section{Determination of $\mathrm{T}$, Tn antigens}

To assess the relative level of short Tn (GalNAc $\alpha 1-\mathrm{O}-\mathrm{Ser} /$ Thr) and $\mathrm{T}$ (Gal $\beta 1$-3GalNAc $\alpha 1-\mathrm{O}-\mathrm{Ser} / \mathrm{Thr})$, sugar antigens in cell lysates and culture medium ELISA tests with specific biotinylated lectins were used. Schematic representation of binding specificity of lectins towards carbohydrate antigens within $\mathrm{O}-$ and $\mathrm{N}$-glycans is presented in Fig. 3. As shown in Fig. $4 \mathrm{a}$, rosmarinic acid at $25-100 \mu \mathrm{M}$ concentration significantly inhibited the level of Tn antigen in cell lysates in dosedependent manner. In culture supernatant, the level of the antigen was much lower than in cell lysates with slight inhibitory effect of 50 and $100 \mu \mathrm{M}$ RA in comparison to untreated control. Tn antigen expression was not correlated with mRNA of p p Gal N A c T2 ( p o l y peptide N acetylgalactosaminyltransferase 2), enzyme responsible for catalyzing the attachment of GalNAc to the polypeptide at the initiation of O-linked glycosylation. RT-PCR results demonstrated non-significant inhibition of ppGalNAcT2 expression by 25 and $50 \mu \mathrm{M}$ RA, with more intense effect with $25 \mu \mathrm{M}$ RA (Fig. 4b). $100 \mu \mathrm{M}$ RA did not influenced ppGalNAcT2 mRNA expression. Inhibitory, dose-dependent effect of RA on T antigen in cell lysates, with significant change at 50,100 $\mu \mathrm{M}$ acid concentration in comparison to untreated control, was revealed (Fig. 5a). In culture supernatant, the significant decrease of the antigen upon RA treatment was demonstrated with all used doses of RA. $\beta 1$ 3 galactosyltransferase (C1GalT1) catalyzes transferring of Gal to Tn antigen forming T structure. C1GalT1 expression was significantly inhibited by all used doses of rosmarinic acid (Fig. 5b).

\section{Determination of sT, sTn antigens}

In sialyl-Tn (sTn) antigen, sialic acid residue is attached to GalNAc-O-Ser/Thr with $\alpha 2-6$ linkage. GalNAc $\alpha 2-$ 6sialyltransferase (ST6GalNAcT1) is a member of sialyltransferases family which catalyzes transferring of sialic acid to GalNAc. 50 and $100 \mu \mathrm{M}$ RA, significantly, dose dependently inhibited sT antigen expression in cell lysates; $25 \mu \mathrm{M}$ of acid did not influence sTn (Fig. 6a). In culture medium, all doses of rosmarinic acid caused significant decrease of sialylated Tn structure. ST6GalNAcTl was inhibited by 25 and $50 \mu \mathrm{M}$ RA. Oppositely, $100 \mu \mathrm{M}$ concentration of acid significantly induced ST6GalNAcT1 mRNA expression (Fig. 6b). Galactose on T antigen, after linking with sialic acid by $\alpha 2-3$ bond, forms sT antigen. Reaction is catalyzed by $\alpha 2-$ 3 sialyltransferase (e.g., ST3GalT1). Rosmarinic acid revealed inhibitory, dose-dependent, significant effect on this antigen expression in cell lysates as well as in culture supernatant (Fig. 7a) what was not correlated with ST3GalT1 mRNA expression (Fig. 7b).

\section{Determination of fucosylated antigens}

To assess the influence of rosmarinic acid on fucosylated sugar antigens in fibroblasts, three lectins were used. They recognize fucose especially at terminal position, not inserted in an oligosaccharide chain, linked by $\alpha 1-2, \alpha 1-3$, and $\alpha 1-6$ to Gal
Fig. 3 Schematic representation of selected carbohydrate antigens on glycans of the human cells as well as binding specificity of lectins applied in the study. T, Tn, sT, and sTn antigens are common structures of O-glycans (a). Fucosylated forms are located especially on terminal positions of $\mathrm{N}$ - or O-glycans (b) or are attached to core GlcNAc of Nglycans. Mannose is present in Nglycans (c). N-acetyllactosaminyl and di N-acetyllactosaminyl structures can be detected within both N- or O-glycoproteins (d)

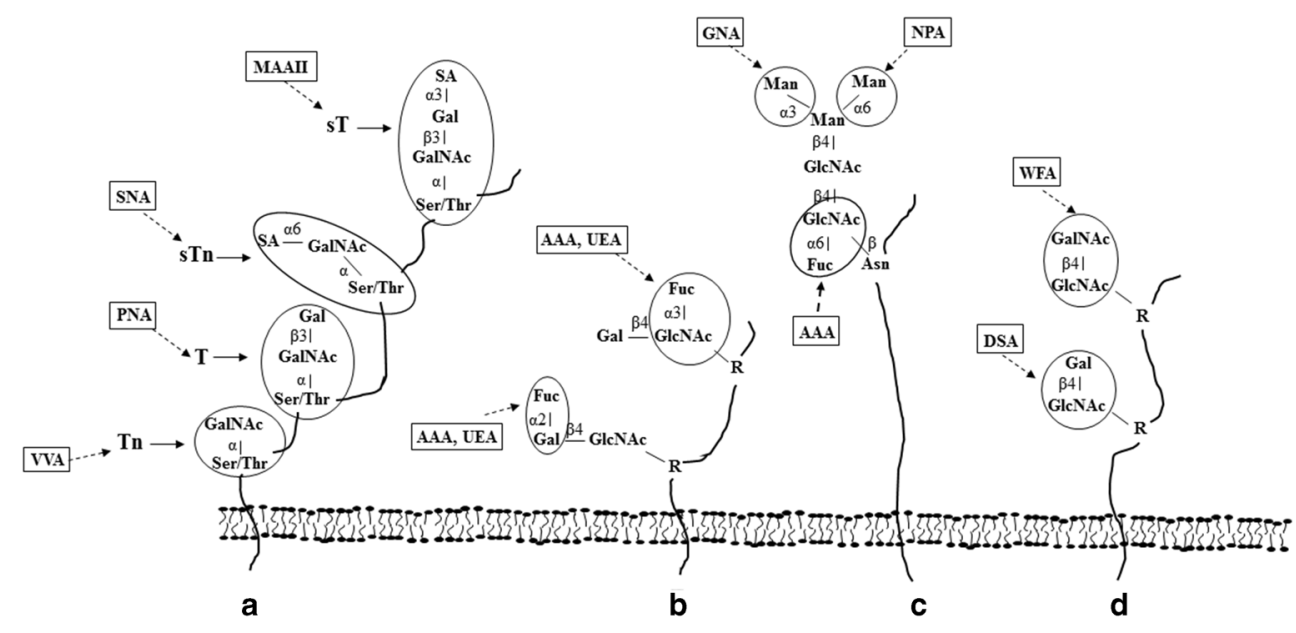




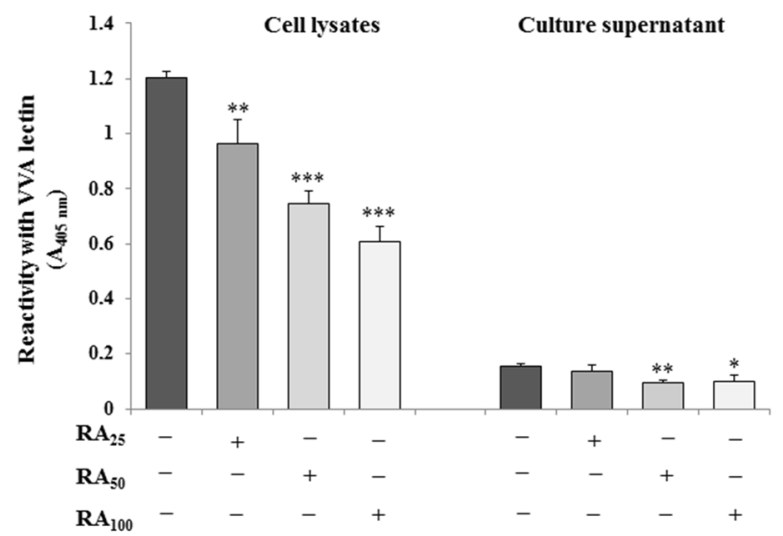

b

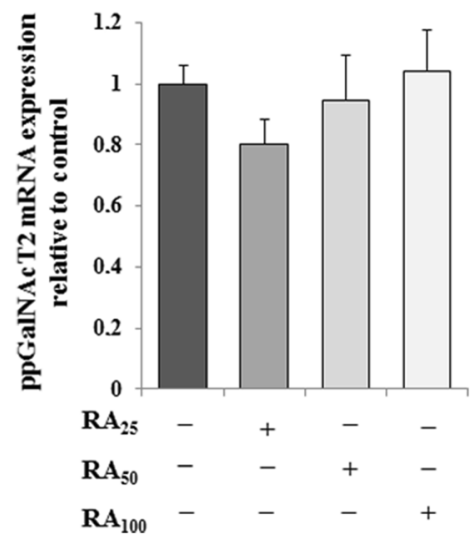

Fig. 4 Effect of RA on Tn antigen (GalNAc $\alpha 1-\mathrm{O}-\mathrm{Ser} / \mathrm{Thr}$ ) expression in skin fibroblasts assayed by ELISA test in cell lysates and culture medium (a) and on ppGalNAcT2 gene determined by RT-PCR (b). The cells were subjected by $25,50,100 \mu \mathrm{M}$ RA for $24 \mathrm{~h}$. In ELISA tests, the same concentrations of proteins $(5 \mu \mathrm{g} / 50 \mu \mathrm{L})$ of cell lysates and $50 \mu \mathrm{L}$ of media were applied. The results are expressed as absorbance at $405 \mathrm{~nm}$

or GlcNAc. In Fig. 8a, not significant effect of RA on Fuc $\alpha 1$ $2 \mathrm{Gal}$ and Fuc $\alpha 1-3 \mathrm{GlcNAc}$ antigens (detected by UEA lectin) in cell lysates was revealed; in culture supernatants, antigen level was very low with slight, statistical inhibitory effect of RA comparing to untreated control. Fucose antigens detected by AAA lectin (with affinity to Fuc $\alpha 1-6 \mathrm{GlcNAc}$; Fuc $\alpha 1$ $2 \mathrm{Gal}$; Fuc $\alpha 1-3 \mathrm{GlcNAc}$ ) were significantly inhibited only with $100 \mu \mathrm{M}$ RA in cell lysates and with all used doses of acid in culture supernatant (with dose-dependent manner) (Fig. 8b). Using LTA lectin with the highest affinity to Fuc $\alpha 1-3 \mathrm{GlcNAc}$, we revealed significant decrease of mentioned antigen in cell lysates (with dose-dependent manner). In culture supernatant, the level of the antigen was very low, with statistical decrease with all used doses of RA (Fig. 8c). after reactivity with VVA lectin. Values \pm S.D are the mean from 3 assays. $* p<0.05$; * $p<0.01 ; * * * p<0.001$. In RT-PCR analysis, the results are expressed as a relative fold change in ppGalNAcT mRNA expression in comparison to control were expression was set as $1 . \pm$ S.D are the mean of triplicate cultures

\section{Determination of $\mathrm{N}$-acetyllactosamine and $\mathrm{di}$ $\mathrm{N}$-acetyllactosamine structures}

$\mathrm{N}$-acetyllactosamine structures are present in branched $\mathrm{N}$ glycans as well as in mucin-type O-glycoforms. Two lectins were used to recognize mentioned sugar antigens: DSA lectin preferentially binding to Gal $\beta 1-4 \mathrm{GlcNAc} / \mathrm{GlcNAc}$ and WFA lectin specifically binding to GalNAc $\beta 1-4$ GlcNAc structure. $\mathrm{N}$-acetyllactosaminyl antigens in cell lysates and culture supernatant remained without significant change upon RA treatment (Fig. 9a). In contrary, di N-acetyllactosaminyl carbohydrate antigen was significantly inhibited by RA, in dosedependent manner, in cells and culture medium when compared with untreated control (Fig. 9b). a

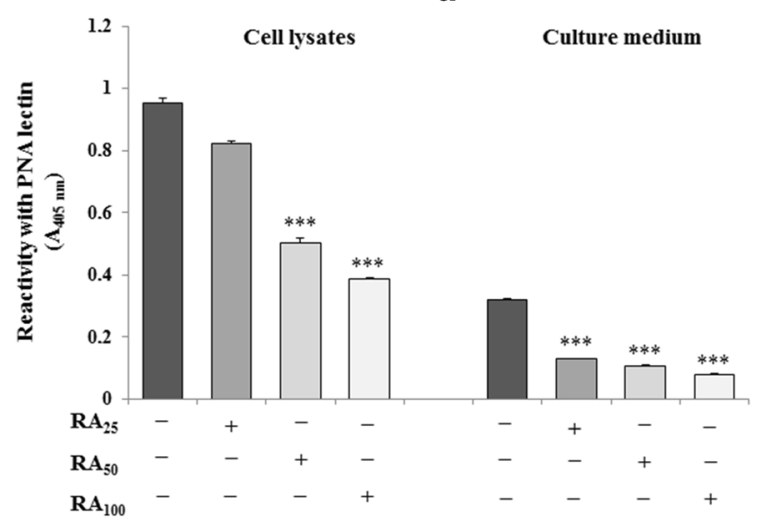

b

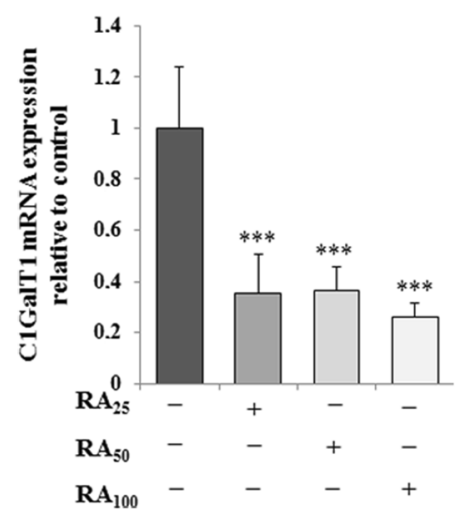

Fig. 5 Effect of RA on T antigen (Gal $\beta 1-3$ GalNAc $\alpha 1-O-S e r / T h r)$ expression in skin fibroblasts assayed by ELISA test in cell lysates and culture medium (a) and on C1GalT1 gene determined by RT-PCR (b). The cells were subjected by 25,50 , and $100 \mu \mathrm{M}$ RA for $24 \mathrm{~h}$. In ELISA tests, the same concentrations of proteins $(5 \mu \mathrm{g} / 50 \mu \mathrm{L})$ of cell lysates and $50 \mu \mathrm{L}$ of media were applied. The results are expressed as absorbance at
$405 \mathrm{~nm}$ after reactivity with PNA lectin. Values \pm S.D are the mean from 3 assays. $* * * p 0.001$. In RT-PCR analysis, the results are expressed as a relative fold change in C1GalT1 mRNA expression in comparison to control were expression was set as $1 . \pm$ S.D are the mean of triplicate cultures. $* * * p<0.001$ 


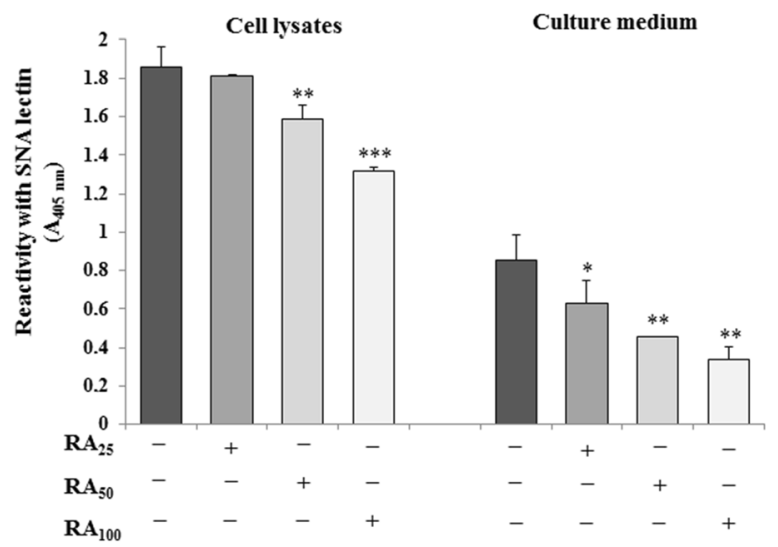

b

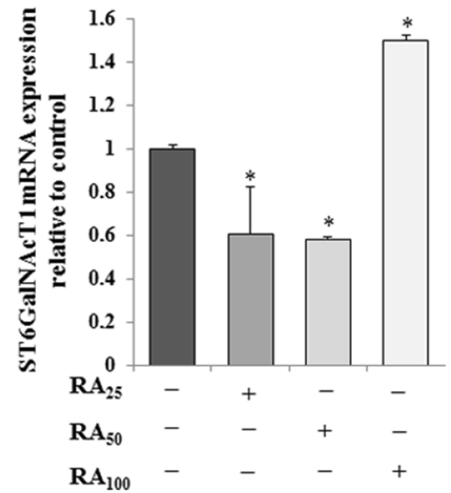

Fig. 6 Effect of RA on NeuAc $\alpha 2-6 \mathrm{Gal} / \mathrm{GalNAc}$ antigen expression in skin fibroblasts assayed by ELISA test in cell lysates and culture medium (a) and on ST6GalNAcT1 gene determined by RT-PCR (b). The cells were subjected by 25,50 , and $100 \mu \mathrm{M}$ RA for $24 \mathrm{~h}$. In ELISA tests, the same concentrations of proteins $(5 \mu \mathrm{g} / 50 \mu \mathrm{L})$ of cell lysates and $50 \mu \mathrm{L}$ of media were applied. The results are expressed as absorbance

\section{Determination of $a 1-3$ and a1-6 mannose sugar antigens}

GNA and NPA lectins bind preferentially to high-mannose Nglycans. GNA identifies Man $\alpha 1-3$ Man and NPA Man $\alpha 1-6$ Man linkages. Rosmarinic acid did not influence significantly Man 1 1-3Man of fibroblasts cell lysates and significantly decreased the mannose carbohydrate antigens in glycoforms released to the culture medium (Fig. 10a). Similar effect of RA on Man $\alpha 1-6$ Man was revealed, however, with significant inhibition of the antigen with $100 \mu \mathrm{M}$ RA in cell lysates (Fig. 10b).

\section{Discussion}

Nowadays, the development of pharmaceutical industry allows the direct use of natural bioactive substances, such as at $405 \mathrm{~nm}$ after reactivity with SNA lectin. Values \pm S.D are the mean from 3 assays. ${ }^{*} p<0.05 ; * * p<0.01 ; * * * p<0.001$. In RT-PCR analysis, the results are expressed as a relative fold change in ST6GalNAcT1mRNA expression in comparison to control were expression was set as $1 . \pm$ S.D are the mean of triplicate cultures. $* p<0.05$

rosmarinic acid, extracted from plants with a high therapeutic power. RA, a common component of many herbs is said to possess many important biological activities, mainly anti-inflammatory, anti-oxidative, anti-apoptotic, and anti-fibrotic (Oliveira et al. 2019; Bahri et al. 2017). Exact mechanism of RA action is not fully understood. It was stated that phenolic hydrogens of acid are able to modulate free radical scavenging; simultaneously, catechols give proper polarity for RA to pass through the lipid bilayers and protect them against oxidation (Amoah et al. 2016). Recently, anti-fibrotic effect of rosmarinic and carnosic acid due to synergistic pro-apoptotic action on lung fibroblasts and myofibroblasts was reported (Bahri et al. 2017). Hahn et al. (2017) revealed inhibitory effect of RA on NF-kB and NF-kB target genes-TNF- $\alpha$, IL-6 in $\mathrm{H}_{2} \mathrm{O}_{2}$-exposed normal human dermal fibroblasts. Zhang et al. (2019) have found that rosmarinic acid alleviated apoptosis of cardiomyocyte via cardiac fibroblasts by a

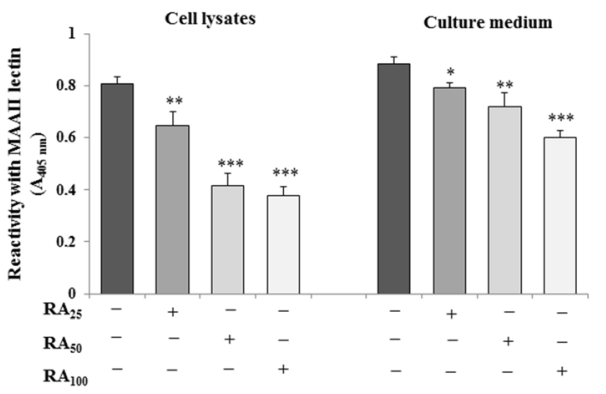

b

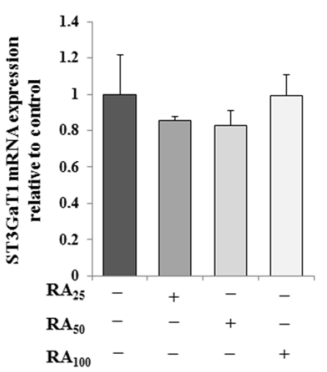

Fig. 7 Effect of RA on NeuAc $\alpha 2-3 \mathrm{Gal}$ antigen expression in skin fibroblasts assayed by ELISA test in cell lysates and culture medium (a) and on ST3GalT1 gene determined by RT-PCR (b). The cells were subjected by 25,50 , and $100 \mu \mathrm{M}$ RA for $24 \mathrm{~h}$. In ELISA tests, the same concentrations of proteins $(5 \mu \mathrm{g} / 50 \mu \mathrm{L})$ of cell lysates and $50 \mu \mathrm{L}$ of media were applied. The results are expressed as absorbance at $405 \mathrm{~nm}$ after reactivity with MAAII lectin. Values \pm S.D are the mean from 3 assays. $* p<0.05 ; * * p<0.01 ; * * p<0.001$. In RT-PCR analysis, the results are expressed as a relative fold change in ST3GalT1mRNA expression in comparison to control were expression was set as $1 . \pm$ S.D are the mean of triplicate cultures. $* p<0.05$ 
Fig. 8 Effect of RA on fucosylated sugar antigens expression in skin fibroblasts assayed by ELISA test in cell lysates and culture medium. To detect Fuc $\alpha 1-2$ Gal; Fuc $\alpha 1$ 3 GlcNAc structures UEA lectin was used (a); for Fuc $\alpha 1$ 6GlcNAc; Fuc $\alpha 1-2$ Gal; Fuc $\alpha 1$ $3 \mathrm{GlcNAc}$, AAA lectin was applied (b) and LTA was used for Fuc $\alpha$ 1-3GlcNAc detection (c).

The cells were subjected by 25 , 50 , and $100 \mu \mathrm{M} \mathrm{RA}$ for $24 \mathrm{~h}$. In ELISA tests, the same

concentrations of proteins $(5 \mu \mathrm{g} /$ $50 \mu \mathrm{L}$ ) of cell lysates and $50 \mu \mathrm{L}$ of media were applied. The results are expressed as absorbance at $405 \mathrm{~nm}$ after reactivity with mentioned lectins. Values \pm S.D are the mean from 3 assays. $* * p<0.01 ; * * * p<0.001$
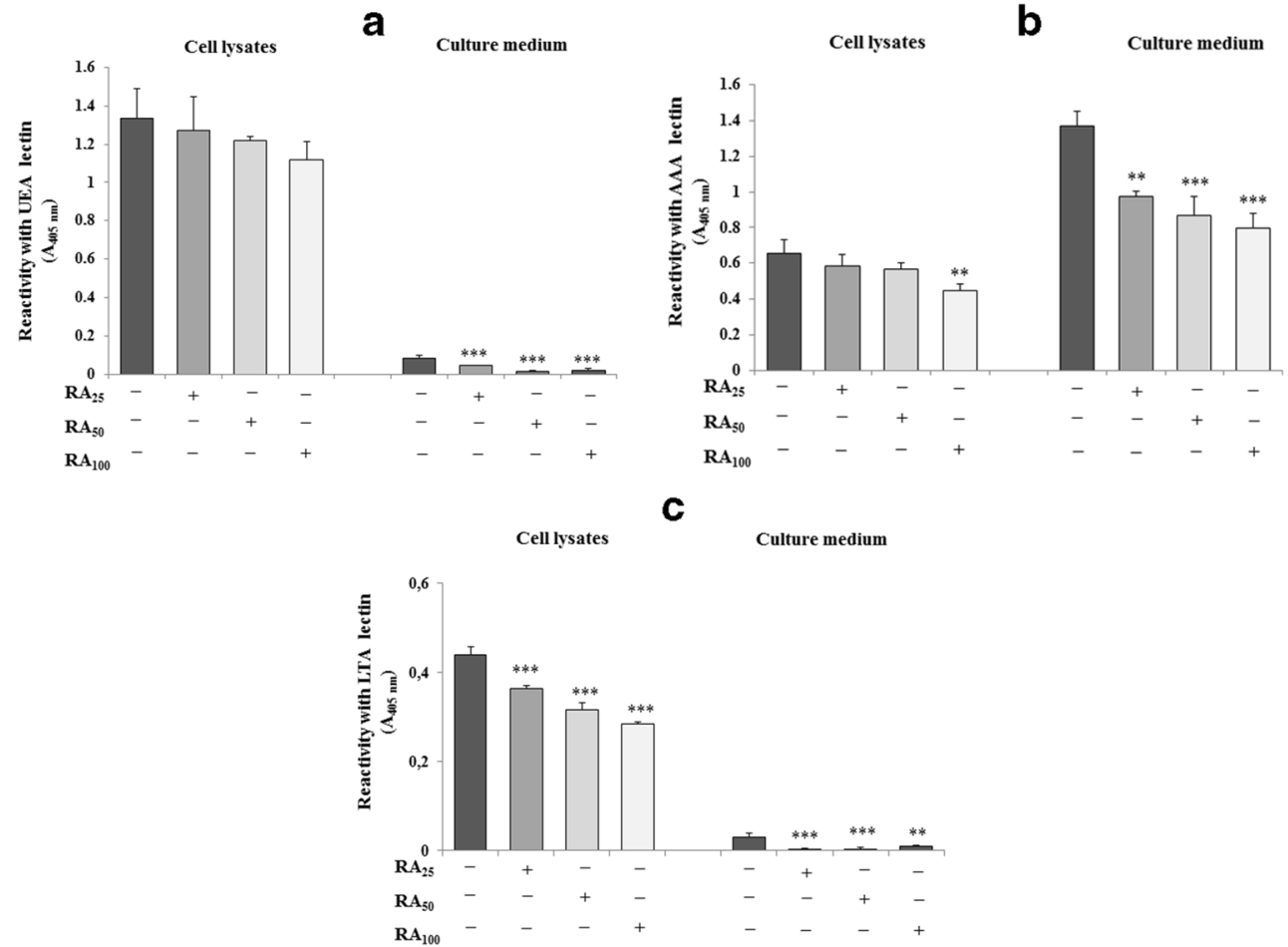

inhibiting the expression and release of FasL. RA has been also reported to have some aging-modulatory and healthpromoting effects on human skin fibroblasts during their replicative lifespan in vitro (Sodagam et al. 2019).

There are limited studies on the effects of RA on fibroblasts, especially their glycosylation, the phenomenon which contributes significantly to fundamental biological functions, such as cell differentiation, cell adhesion, cell-cell interaction, and regulation of signaling pathways (Itakura et al. 2016). In our study, we assessed the expression of specific sugar antigens and mRNA of selected glycosyltransferases in human skin fibroblasts administrated with 25, 50, and $100 \mu \mathrm{M}$ rosmarinic acid.

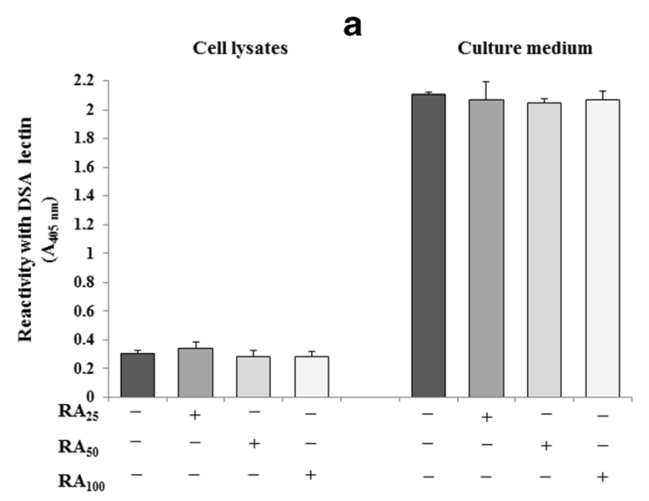

Fig. 9 Effect of RA on Gal $\beta 1-4 G l c N A c ;$ GlcNAc (detected by DSA lectin) (a) and GalNAc $\beta 1-4$ GlcNAc (detected by WFA lectin) (b) sugar antigens expression in skin fibroblasts assayed by ELISA test in cell lysates and culture medium. The cells were subjected by 25,50 ,
Glycosylation can be understood as covalent attachment of a carbohydrate to protein, lipid, other carbohydrate, and also other organic compound. The process is catalyzed by specific glycosyltransferases, using sugar donor substrates. Generally, there are two most common types of glycosylation: $\mathrm{O}-$ and $\mathrm{N}$ glycans. There is a very high frequency of O-glycosylation on secreted and membrane-bound glycoproteins (e.g., mucins which are rich in serine and threonine) (Reis et al. 2010). Tn antigen (GalNAc $\alpha 1-\mathrm{O}-\mathrm{Ser} / \mathrm{Thr}$ ) is the simplest form of $\mathrm{O}$ glycans formed with the participation of specific $\mathrm{N}$ acetylgalactosylaminyltransferase (ppGalNAcT) (Ten et al. 2003). Gal-transferase (C1GalT1) syntheses T antigen formation. Alternatively, both antigens can be sialylated by proper

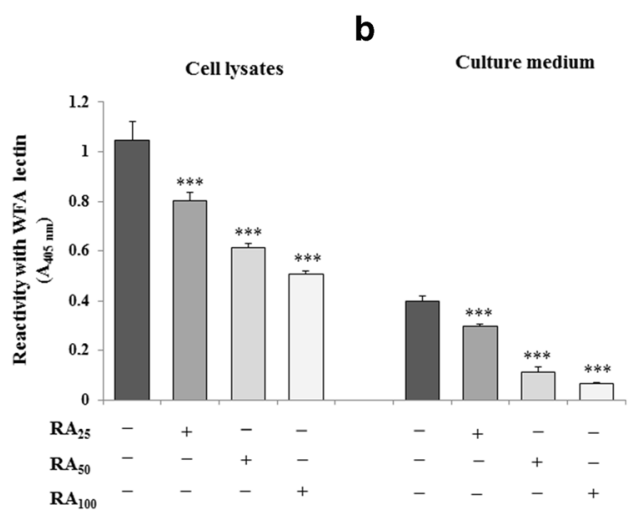

$100 \mu \mathrm{M}$ RA for $24 \mathrm{~h}$. In ELISA tests, the same concentrations of proteins $(5 \mu \mathrm{g} / 50 \mu \mathrm{L})$ of cell lysates and $50 \mu \mathrm{L}$ of media were applied. The results are expressed as absorbance at $405 \mathrm{~nm}$ after reactivity with mentioned lectins. Values \pm S.D are the mean from 3 assays. $* * * p<0.001$ 


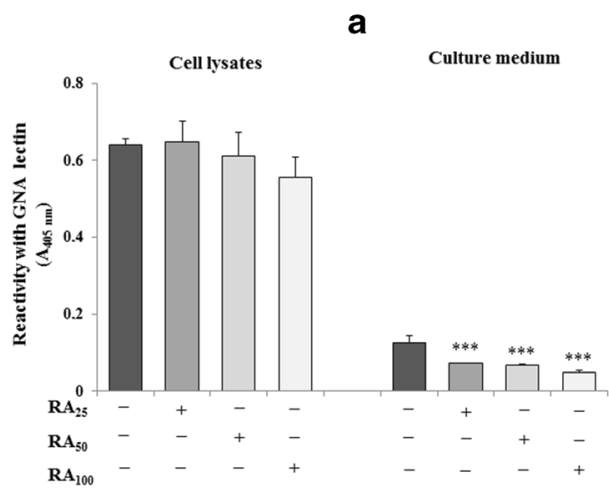

Fig. 10 Effect of RA on mannose sugar antigens expression in skin fibroblasts assayed by ELISA test in cell lysates and culture medium. To detect Man $\alpha 1$-3Man antigen GNA lectin was used (a), for Man $\alpha 1$ 6Man structure NPA lectin was applied (b). The cells were subjected by

sialyltransferases forming sialyl-Tn or sialyl-T antigens. Sialic acid, with strong electronegative charges, contributes to many cellular functions, e.g., migration and proliferation being functionally involved in developmental and pathological states. Formation of sTn antigen stops any further processing of the oligosaccharide chain. We revealed that $\mathrm{Tn}$ and $\mathrm{T}$ antigens as well as their sialylated forms present in fibroblasts cell lysates were inhibited by rosmarinic acid. However, these results did not correlate with mRNA expression of glycosyltransferases catalyzing Tn, sTn, and sT sugar antigens formation. One possible explanation of such discrepancy can be that rosmarinic acid influenced the level of mentioned antigens by other signaling pathways which were not explored in the study. Generally, it is known that exploring the protein glycosylation process is difficult and challenging, e.g., due to high heterogeneity of sugar forms and mentioned above different ways of regulation of the process (Jensen et al. 2010). Core 1 C1GalT1 is a mucin-type glycosyltransferase playing critical role in many biological functions. It has been demonstrated to regulate angiogenesis, thrombopoiesis. $\mathrm{T}$ antigen formed by this enzyme is the precursor for subsequent extension and maturation of mucin-type O-glycans (Wu et al. 2013). We revealed inhibitory effect of RA on C1GalT1 mRNA and we can state that it resulted in the decrease of Galß1-3GalNAc. We can also assume that in this way, rosmarinic acid could reduce formation of fully branched glycans.

Special for fucose is its almost exclusive presence at a terminal position, i.e., not inserted in an oligosaccharide chain. Therefore, structural alterations in these terminal glycan epitopes are associated to changes in many biological properties of cells. Fucose seems to play a crucial role in biological recognition events, such as cell-cell and cell-matrix interactions (Ma et al. 2006). The fucose molecule is present in $\mathrm{ABH}$ blood group antigens and in some oligosaccharide structures belonging to the Lewis ${ }^{\mathrm{x}}$, Lewis ${ }^{\mathrm{y}}$, Lewis ${ }^{\mathrm{a}}$, and Lewis ${ }^{\mathrm{b}}$ antigens (Orczyk-Pawiłowicz 2007). As we revealed in our study, fucosylated antigens are present in human fibroblasts and their

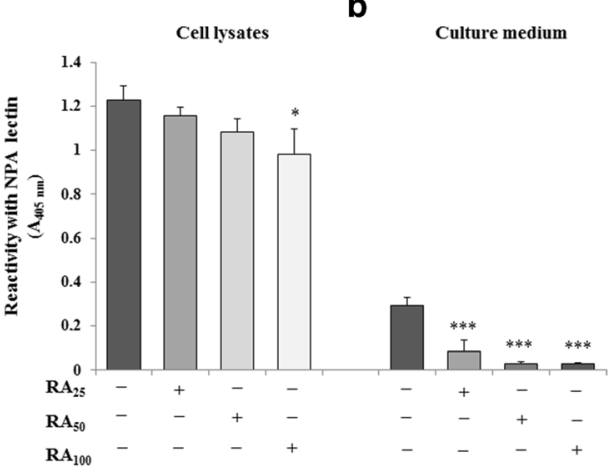

25, 50, and $100 \mu \mathrm{M}$ RA for $24 \mathrm{~h}$. In ELISA tests, the same concentrations of proteins $(5 \mu \mathrm{g} / 50 \mu \mathrm{L})$ of cell lysates and $50 \mu \mathrm{L}$ of media were applied. The results are expressed as absorbance at $405 \mathrm{~nm}$ after reactivity with mentioned lectins. Values \pm S.D are the mean from 3 assays. $* * * p<0.001$

expression is effected by rosmarinic acid. We suggest that revealed in our study inhibitory effect of RA especially on Fuc $\alpha 1-3$ GlcNAc (Lewis $\mathrm{x}$ ) in glycoproteins of cell lysates or Fuc $\alpha 1-2$ Gal, Fuc $\alpha 1-3$ GlcNAc (Lewis y) in glycoproteins released to the culture medium can change the adhesion properties of the cells to other cells as well as to the components of extracellular matrix.

GalNAc $\beta 1-4$ GlcNAc is one more antigen which expression was inhibited by RA action in cell lysates and in culture supernatant. It is interesting that very similar structure $\mathrm{N}$ acetyllactosaminyl structure (Gal $\beta 1-4 \mathrm{GlcNAc} / \mathrm{GlcNAc})$ with a lack of $\mathrm{N}$-acetylation on galactose in comparison with GalNAc $\beta 1-4$ GlcNAc was not effected by rosmarinic acid. One possible explanation of this result can be different localization of both antigens within glycoprotein chains and different availability of RA to them. Apart from that, it is said that specific glycans attached to some proteins and lipids may be physiologically inert. Such "environmentally friendly" glycation might impart subtle characteristic to glycoproteins that become valuable in response to new selective pressure applied by exogenous and pathogenic stimuli (Ohtsubo and Marth 2006).

Man $\alpha 1-3$ Man and Man $\alpha 1-6$ Man are common antigens for $\mathrm{N}$-glycoproteins (most likely on high- and oligomannose Nglycans). It is said that $\mathrm{N}$-linked glycans serve as "universal signals" to modulate and control N-glycoprotein folding. Nlinked glycans can direct the folding machinery to defined regions of the polypeptide and specific N-linked glycans can be used as covalently attached signals to control the process (Shental-Bechor and Levy 2008). Rosmarinic acid weakly effected both mannose antigens. Again, this can be explained by poor availability of the RA molecule to typically branched $\mathrm{N}$-oligosaccharide chain.

Summarizing, we can state that rosmarinic acid effected most sugar antigens of human skin fibroblasts examined in the study. We suggest that this inhibitory outcome can influence some of the crucial carbohydrate functions involved 
especially in cells adhesion and cell-cell interactions. Recently, it was demonstrated that glycosylation of glycoproteins of human skin fibroblasts is changed during aging and the senescent process (Itakura et al. 2016). According to this, we conclude that rosmarinic acid can also have kind of agingmodulatory effect on skin fibroblasts. However, to support the idea, the subject should be explored in the future to determine the mechanism of RA action.

Author contribution statement RI designed and performed experiments, analyzed the data, and wrote the article; SK performed part of the experiments and analyzed the data.

Funding information This work received financial support from the Medical University of Białystok, grant number: N/ST/ZB/16/004/2203.

\section{Compliance with ethical standards}

Conflict of interest The authors declare that there is no conflict of interest.

Open Access This article is distributed under the terms of the Creative Commons Attribution 4.0 International License (http:// creativecommons.org/licenses/by/4.0/), which permits unrestricted use, distribution, and reproduction in any medium, provided you give appropriate credit to the original author(s) and the source, provide a link to the Creative Commons license, and indicate if changes were made.

\section{References}

Amoah SKS, Sandjo LP, Kratz JM, Biavatti MW (2016) Rosmarinic acid - pharmaceutical and clinical aspects. Planta Med 82:388-406

Bahri S, Mies F, Ali RB, Mika M, Jameleddine S, Mc Entee K, Shlyonsky V (2017) Rosmarinic acid potentiates carnosic acid induced apoptosis in lung fibroblasts. PLoS One 12:9

Carmichael J, Degraff W, Gazdar A, Minna J, Mitchell J (1987) Evaluation of a tetrazolium-based semi automated colorimetric assay: assessment of chemosensitivity testing. Cancer Res 47:936942

Cui J, Zheng H, Zhang J, Jia L, Feng Y, Wang W, Li H, Chen F (2017) Profiling of glycan alterations in regrowing limb tissues of Cynops orientalis. Wound Repair Regen 25:836-845

Hahn HY, Kim KB, An I, Ahn KJ, Han HJ (2017) Protective effects of rosmarinic acid against hydrogen peroxide-induced cellular senescence and the inflammatory response in normal human dermal fibroblasts. Mol Med Rep 16:9763-9769

Haltiwanger RS, Lowe JB (2004) Role of glycosylation in development. Annu Rev Biochem 73:491-537
Itakura Y, Sasaki N, Kami D, Gojo S, Umezawa A, Toyoda M (2016) Nand O-glycan cell surface protein modifications associated with cellular senescence and human aging. Cell Biosci 6:14

Jensen PH, Kolarich D, Packer NH (2010) Mucin-type O-glycosylationputting the pieces together. FEBS J 277:81-94

Karthik D, Viswanathan P, Anuradha CV (2011) Administration of rosmarinic acid reduces cardiopathology and blood pressure through inhibition of p22phox NADPH oxidase in fructose-fed hypertensive rats. J Cardiovasc Pharmacol 58:514-521

Ma B, Simala-Grant JL, Taylor DE (2006) Fucosylation in prokaryotes and eukaryotes. Glycobiology 16:158R-184R

Ohtsubo K, Marth JD (2006) Glycosylation in cellular mechanisms of health and disease. Cell 126:855-867

Oliveira JR, Camarago SEA, Oliviera LD (2019) Rosmarinus officinalis L. (rosemary) as therapeutic and prophylactic agent. J Biomed Sci 26:5

Orczyk-Pawiłowicz M (2007) The role of fucosylation of glycoconjugates in health and disease. Post Hig Med Dośw 61: 240-252

Reis CA, Osorio H, Silva L, Gomes C, David L (2010) Alteration in glycosylation as biomarkers for cancer detection. J Clin Pathol 63: 322-329

Sasaki N, Itakura Y, Toyoda M (2017) Sialylation regulates myofibroblast differentiation of human skin fibroblasts. Stem Cell Res Ther 8:81

Scheckel KA, Degner SC, Romagnolo DF (2008) Rosmarinic acid antagonizes activator protein-1-dependent activation of cyclooxygenase- 2 expression in human cancer and nonmalignant cell lines. J Nutr 138:2098-2105

Shental-Bechor D, Levy Y (2008) Effect of glycosylation on protein folding: a close look at thermodynamic stabilization. Proc Natl Acad Sci U S A 105:8256-8261

Sodagam L, Lewinska A, Kwasniewicz E, Kokhanovska S, Wnuk M, Siems K, Rattan SIS (2019) Phytochemicals Rosmarinic acid, ampelopsin, and amorfrutin-A can modulate age-related phenotype of serially passaged human skin fibroblasts in vitro. Front Genet 10: 18

Ten HKG, Fritz TA, Tabak LA (2003) All in the family: the UDPGalNAc:polypeptide N-acetylgalactosaminyltransferases. Glycobiology 275:38197-38205

Wu YM, Liu CH, Huang MJ, Lai HS, Lee PH, Hu RH, Huang MC (2013) C1GALT1 enhances proliferation of hepatocellular carcinoma cells via modulating MET glycosylation and dimerization. Cancer Res 73:5680-5690

Zhang X, Zhu JX, Ma ZG, Wu HM, Xu SC, Song P, Kong CY, Yuan YP, Deng W, Tang QZ (2019) Rosmarinic acid alleviates cardiomyocyte apoptosis via cardiac fibroblast in doxorubicin-induced cardiotoxicity. Int J Biol Sci 15:556-567

Publisher's note Springer Nature remains neutral with regard to jurisdictional claims in published maps and institutional affiliations. 